\title{
CARACTERIZAÇÃO E COMPORTAMENTO MECÂNICO DE AÇO INOXIDÁVEL FERRÍTICO*
}

Guilherme Filipe de França Vieira ${ }^{1}$ Gigliola Salerno ${ }^{2}$

\section{Resumo}

Os aços inoxidáveis ferríticos apresentam menor custo que os austeníticos, pois praticamente não possuem níquel em sua composição, e seu custo está diretamente ligado ao preço do níquel que possui alta volatilidade. Devido a sua capacidade de resistência à corrosão, estruturas são construídas a partir deste material e descartam a necessidade de revestimento contra corrosão. O trabalho tem como objetivo caracterizar o comportamento mecânico da liga de aço inoxidável ferrítico, UNS S43932. Metalografia e dureza foram realizadas para caracterizar o material e sua microestrutura. Por meio de ensaios mecânicos de tração, no equipamento MTS $250 \mathrm{kN}$, analisando sete corpos de prova, obtiveram-se propriedades como: módulo de elasticidade, tensão de escoamento, tensão limite de resistência à tração, tensão de ruptura, alongamento, redução de área, coeficiente de resistência e expoente de encruamento, através da curva monotônica. Pode-se observar que as propriedades mecânicas identificadas estão coerentes com aquelas fornecidas pelo fabricante, 0 que validou os ensaios e possibilitou a adicional obtenção de propriedades mecânicas referentes ao comportamento da parcela plástica.

Palavras-chave: Comportamento mecânico; Aço inoxidável ferrítico.

\section{CARACTERIZATION AND MECHANICAL BEHAVIOR OF FERRITIC STAINLESS STEEL}

\section{Abstract}

Ferritic stainless are less expensive than the austenitic one, because of nickel quantity. It presents high corrosion resistance which improves its structural applications. The purpose of this work is characterize mechanical behavior of ferritic stainless steel, UNS S43932. Metallography and hardness tests characterized the material and its microstructure. This method is interesting by considering the portion elastic and plastic, to estimate the material behavior. Tension tests were conducted at the universal equipment testing MTS $250 \mathrm{kN}$, seven specimens were analyzed, and were estimated elastic modulus, tensile and yield strength, elongation, resistance coefficient and hardening exponent. Mechanical properties evaluated were similar to the producer plate data and, additional plastic region dominated mechanical properties were identified.

Keywords: Mechanical behavior; Ferritic stainless.

Graduando em Engenharia Mecânica, 8º semestre, FEI, São Bernardo do Campo, SP, Brasil.

Engenharia Mecânica, Doutora, Orientadora, Professora do Departamento de Engenharia de Materiais, FEI, São Bernardo do Campo, SP, Brasil. 


\section{INTRODUÇÃO}

A adição de cromo no aço aumenta sua resistência à corrosão e oxidação, os aços com teores de cromo superiores a $12 \%$, são classificados como aços inoxidáveis. Nenhum material é absolutamente inoxidável, sua resistência aumenta de acordo com o teor de cromo, e outros elementos de liga com função anticorrosiva [1].

O material em estudo (UNS S43932) possui pouca base de dados conhecida, por apresentar características intermediárias entre os aços inoxidáveis, o conhecimento de suas propriedades ainda não foi completamente explorado, porém este material é uma solução atraente quanto aos custos, pois apresenta custo inferior aos aços mais nobres, porém suas características relativas à corrosão concedem uma atenção especial, possibilitando sua utilização em condições severas de operação. Suas maiores aplicações estão relacionadas a sistemas de exaustão, tubos para trocadores de calor, e peças soldadas para máquinas de lavar, etc. [1].

Os aços inoxidáveis ferríticos são ligas de $\mathrm{Fe}+\mathrm{Cr}$, que possuem em sua maioria teores de cromo mais elevados do que os martensíticos, possuem concentração de carbono de até $0,76 \%$. Apesar de possuírem o nome ferrítico, em sua maioria estes aços possuem em sua microestrutura de 30 a $50 \%$ de austenita quando aquecidos acima de $800^{\circ} \mathrm{C}$, ao resfriá-los, a austenita formará martensita, e a estrutura será composta por uma mistura de ferrita e martensita $[1 ; 2 ; 3]$. Os aços inoxidáveis ferríticos possuem menor dureza e ductilidade em comparação com os austeníticos, possibilitando que uma trinca se inicie com menor energia do que em aço inoxidável austeníticos. Em testes de fadiga por esforços axiais e de flexão, com ciclos de $10^{6} \mathrm{a}$ $10^{8}$, obteve-se limites de resistência à fadiga de 276 a $324 \mathrm{MPa}$ [4]. Propriedades a tração e dureza podem ser observadas na tabela 1.

Tabela 1: Propriedades mecânicas da liga UNS S43932 [5;6].

\begin{tabular}{|c|c|c|c|}
$\begin{array}{c}\text { Limite de } \\
\text { Escoamento }\end{array}$ & $\begin{array}{c}\text { Limite de } \\
\text { Resistência }\end{array}$ & Dureza & $\begin{array}{c}\text { Módulo de } \\
\text { Elasticidade }\end{array}$ \\
\hline $305 \mathrm{MPa}$ & $460 \mathrm{MPa}$ & $178 \mathrm{HV}$ & $210 \mathrm{GPa}$ \\
\hline
\end{tabular}

Para caracterização do comportamento mecânico, foi feita a caracterização melatográfica do material para identificar a microestrutura de acordo com ASM Metals Handbook [7] Ensaios de tração foram realizados com o intuito de definir as propriedades à tração necessárias para a caracterização da fadiga controlada por deformação em flexão alternada $R=-1$, segundo as normas ASTM E606 e B593 [8;9]. Os ensaios de dureza foram conduzidos de acordo com a norma E384, e a escala escolhida foi Vickers [10]. A medida do tamanho de grão da liga foi realizada através eletronicamente, pelo método dos grãos interceptados, em conformidade com a norma ASTM E112 [11]. Após o levantamento das propriedades, foi possível comparar os dados obtidos com os fornecidos pela Aperam (tabela 1), e as propriedades relativas ao comportamento mecânico e ainda propriedades desconhecidas foram estimadas.

\section{MATERIAIS E MÉTODOS}

O material utilizado neste projeto é uma liga de aço inoxidável ferrítico UNS S43932 (tabela 2). A liga foi produzida em chapas pela empresa Aperam $[5 ; 6]$. 
Tabela 2: Composição da liga UNS S43932 [5;6].

\begin{tabular}{|c|c|c|c|c|c|c|c|c|}
\hline UNS & $\mathrm{C}$ & $\mathrm{Mn}$ & $\mathrm{Si}$ & $\mathrm{P}$ & $\mathrm{S}$ & $\mathrm{Cr}$ & $\mathrm{Ni}$ & $\mathrm{N}$ \\
\hline S43932 & $0,03 \%$ & $1 \%$ & $1 \%$ & $0,04 \%$ & $0,02 \%$ & $17 \mathrm{a} 19 \%$ & $0,50 \%$ & $0,03 \%$ \\
\hline
\end{tabular}

\subsection{Microestrutura}

Para a visualização da microestrutura da liga, foram cortadas amostras longitudinais de $1 \mathrm{~cm}^{2}$ de área, e transversais de $0,0133 \mathrm{~cm}^{2}$ de área, posteriormente foi realizado o embutimento em baquelite (figura 1).

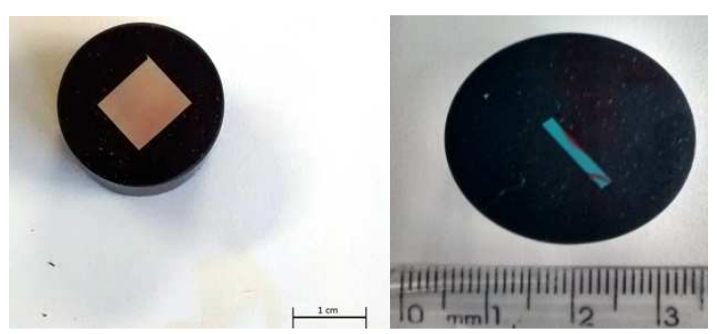

Figura 1: Amostras longitudinal e transversal, respectivamente embutidas em baquelite.

As amostras foram polidas em equipamento de polimento automático, onde foram feitos os processos de lixamento e polimento, com a seguinte sequência de granulações de lixa: 220, 320, 400 e 600; seguidas de polimento com os panos de granulações 6,3 e $1 \mu \mathrm{m}$, respectivamente. O lubrificante utilizado no lixamento foi água em abundância, para o polimento o lubrificante foi álcool em abundância. A pressão empregada foi de $90 \mathrm{~N}$.

Após a superfície ser uniformizada e polida foi necessário reagir à amostra com o objetivo de que a corrosão fosse mais acentuada nos contornos de grão, para a revelação dos mesmos. Como a liga possui fases diferentes em sua composição (ferrita mais carbonetos) a corrosão se dá de maneiras diferentes em cada fase, sendo possível visualizá-las independentemente. Foram testados os reagentes, Vilela (1g de ácido pícrico, $100 \mathrm{ml}$ de álcool etílico e $5 \mathrm{ml}$ de ácido clorídrico) com tentativas de 100, 200 e 300 segundos de imersão e sem corrente; Ralph (50 mL de $\mathrm{H}_{2} \mathrm{O}$, etanol, metanol, e ácido clorídrico, $1 \mathrm{~g}$ de cloreto de cobre II, $3,5 \mathrm{~g}$ de cloreto de ferro III, 2,5 g de ácido nítrico) com tentativas de 100, 200 e 300 segundos de imersão e sem corrente; solução de ácido oxálico a $10 \%$ de concentração $(100 \mathrm{~mL}$ de $\mathrm{H}_{2} \mathrm{O}, 10 \mathrm{~mL}$ de ácido oxálico) durante 300 segundos de reação e uma corrente de $1 \mathrm{~A}$. Todos os reagentes, exceto ácido oxálico (no qual há a necessidade de uma corrente elétrica), possuíam o mesmo procedimento, imersão em solução ácida com tempo controlado seguido de lavagem em água corrente e posterior limpeza com álcool [7].

\subsubsection{Tamanhos de grão}

Este procedimento teve como objetivo a especificação do tamanho de grão da amostra em estudo. Para tanto, foi utilizado o software Stream Essentials, Olympus. O software calcula o tamanho de grão baseado em uma fotomicrografia, com aumento especificado. O método de análise escolhido foi "tamanho de grão por intercepto", em conformidade com a norma ASTM E112 [11], no qual alguns círculos concêntricos são gerados sobre a imagem, e o controlador marca nas linhas geradas os pontos de interceptação dos contornos de grão. Por intermédio destes pontos é calculado uma média entre os tamanhos dos grãos interceptados [11]. 


\subsection{Microdureza}

O ensaio de microdureza, conduzido no equipamento HMV - 2 Shimizu, em escala Vickers, de acordo com a norma ASTM E384 [10], foram feitas 5 medições em cada corpo de prova. $O$ indentador pressionou a amostra por 15 segundos com uma carga de $0,5 \mathrm{~kg}$. Devido à pressão do identador a amostra sofre uma deformação plástica e através da impressão deixada, obtêm-se a medida do comprimento de suas diagonais, por meio destes valores a dureza é obtida, na escala escolhida [10].

\subsection{Ensaio de Tração}

Este ensaio foi realizado com a intenção de obter as propriedades mecânicas relativas à tração, como Módulo de Elasticidade $(\mathrm{E})$, Limite de Escoamento $\left(\sigma_{e}\right)$, Limite de Ruptura $\left(\sigma_{f}\right)$, Limite de Resistência $\left(\sigma_{r}\right)$. O ensaio foi conduzido de acordo com a norma ASTM E8 [12]. A velocidade de escoamento adotada foi de 0,8 $\mathrm{mm} / \mathrm{min}$ até a retirada do extensômetro, a partir deste ponto a velocidade foi de 4 $\mathrm{mm} / \mathrm{min}$. Para a realização do ensaio utilizou-se o equipamento MTS 810 Material Test System, com capacidade carga de $250 \mathrm{kN}$ (figura 2). Foi utilizado um extensômetro da marca MTS, com curso útil de $25 \mathrm{~mm}$. O corpo de prova, com dimensões de acordo ASTM E8 [12], foi confeccionado em um equipamento de corte a jato d'água, onde um "fio de corte" formado por um jato de água pressurizada e um aglomerante corta materiais de diversas naturezas, com alta precisão (figura 3) [12].

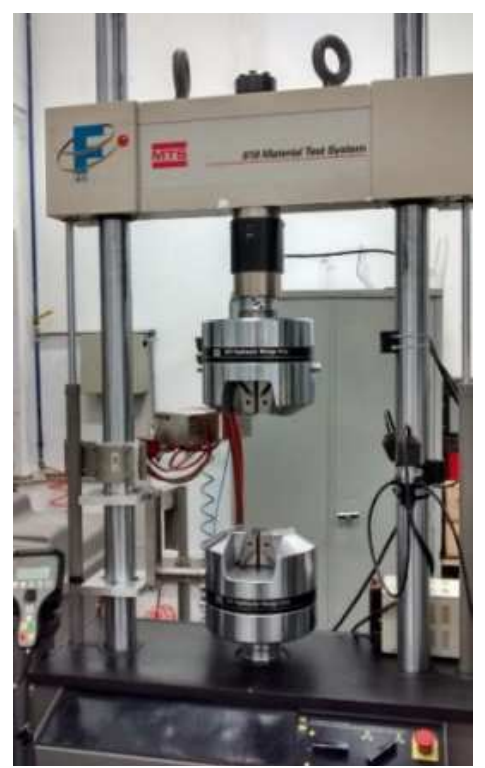

Figura 2: Equipamento universal de ensaios, utilizado no ensaio de tração, capacidade $250 \mathrm{kN}-$ LabMat-FEl.

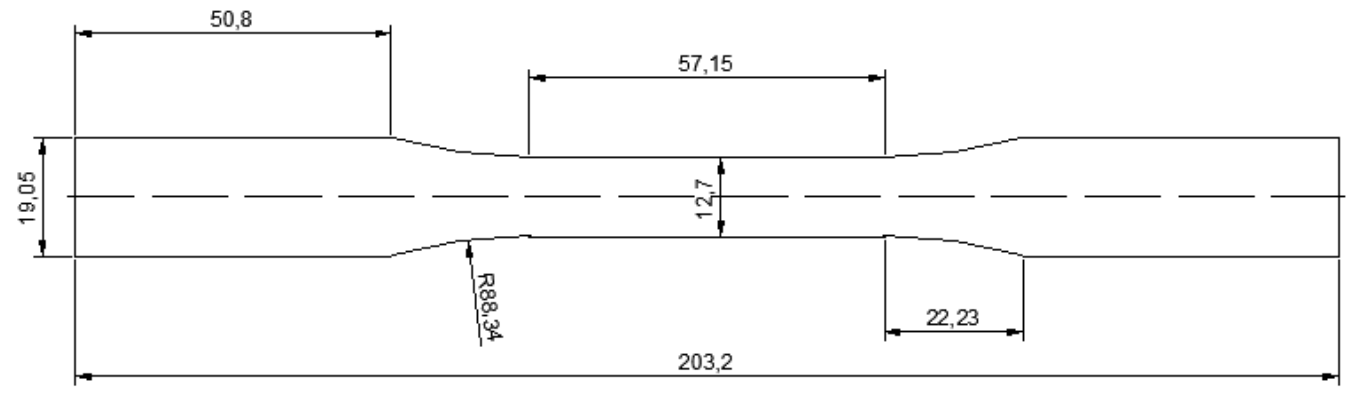

Figura 3: Corpo de prova para ensaio de tração, dimensões em milímetros. 


\section{RESULTADOS E DISCUSSÃO}

\subsection{Microestrutura}

Ao analisar as amostras no microscópio, devido ao grau de refração e altura diferente das fases após a corrosão ficou evidente a distinção entre elas (figura 6), possibilitando a visualização da matriz ferrítica e os precipitados de carbonetos. Devido ao alto teor de cromo da liga que confere a resistência à corrosão, a reação de oxidação necessitou de um tempo longo de exposição para ocorrer evidenciando - caráter inoxidável da liga, pois a sua camada apassivadora era espessa demandando um tempo longo para alcançar a superfície da liga.

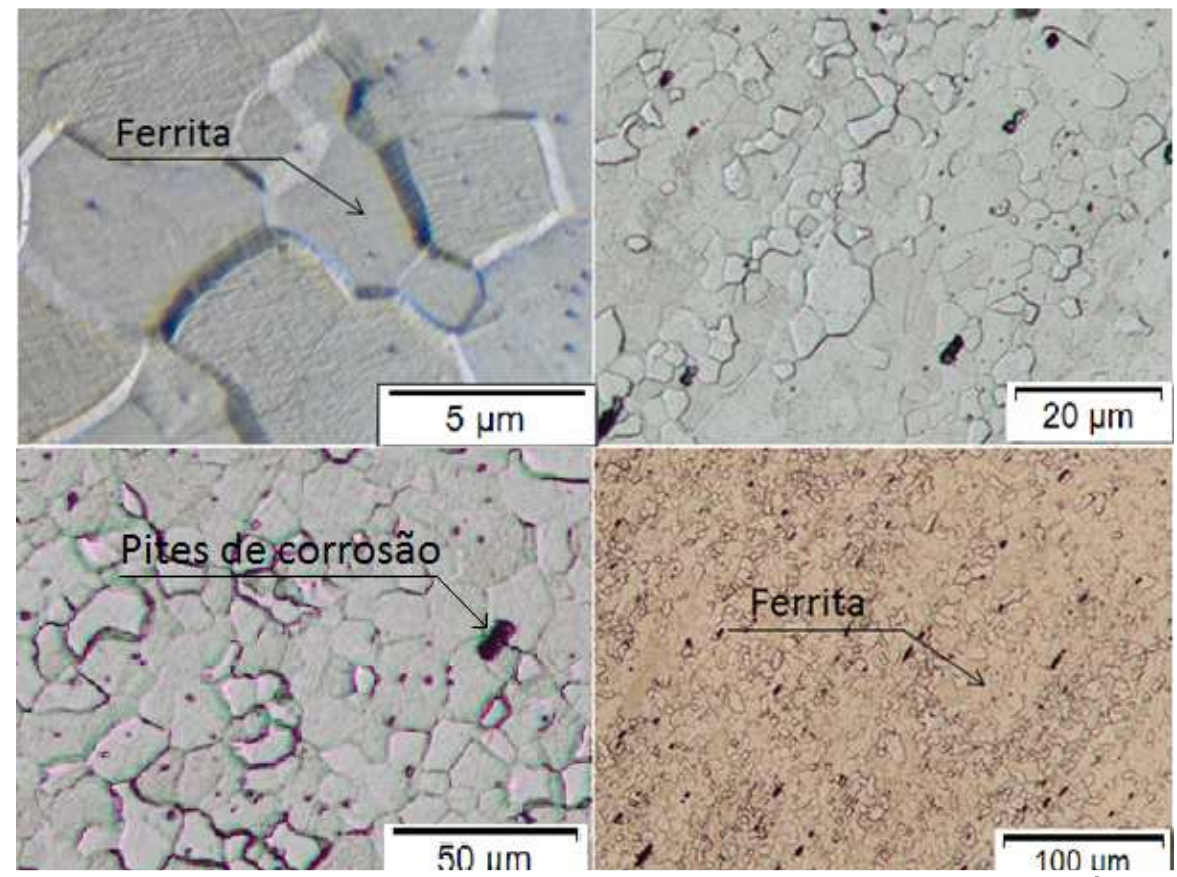

Figura 6: Ampliações em 1000X, 200X, 100X, 50X, respectivamente, reagidas com ácido oxálico, com indicação da fase ferrítica e os possíveis pites de corrosão.

\subsection{Microdureza}

O resultado obtido através da média aritmética de todos os valores foi de $167 \mathrm{HV} 0,5$ $\mathrm{kg}$ (tabela 3), sendo que as distâncias entre as marcas evitam a influência de uma de zona de deformação em relação à próxima medição (figura 7); o resultado obtido foi próximo do esperado, que era 178 HV 0,5 kg (tabela 1).

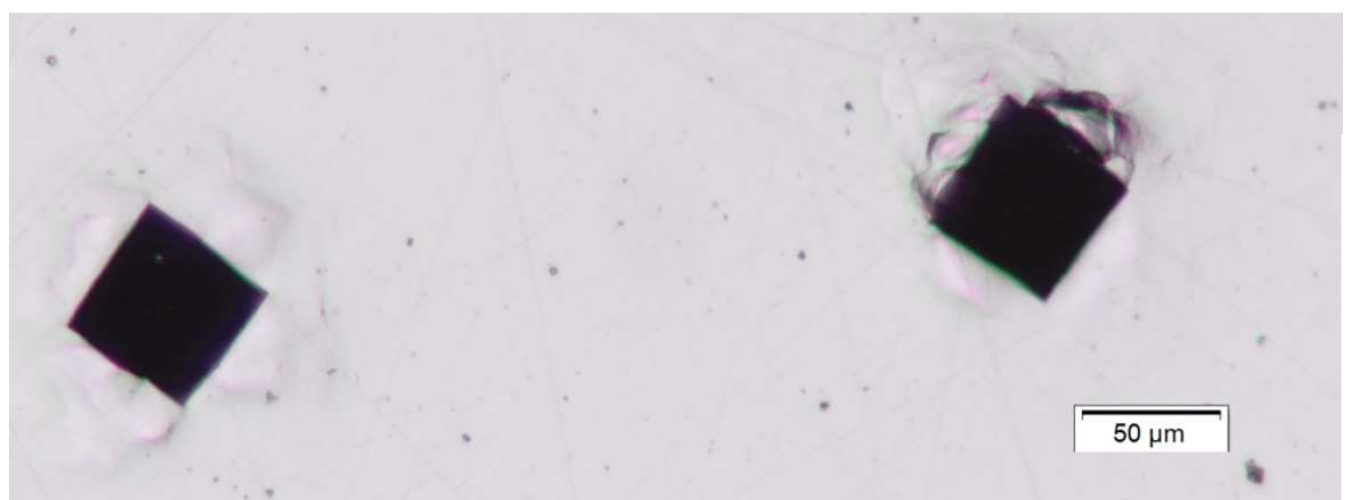

Figura 7: Marcas das indentações Vickers, 100X. 
Tabela 3: Resultados experimentais de microdureza Vickers.

Medição Amostra 1 Amostra 2 Amostra 3 Amostra 4 Amostra 5

\begin{tabular}{cccccc}
\hline 1 & 168 & 178 & 162 & 184 & 147 \\
\hline 2 & 170 & 176 & 172 & 183 & 145 \\
\hline 3 & 171 & 177 & 164 & 178 & 149 \\
\hline 4 & 156 & 183 & 169 & 172 & 154 \\
\hline 5 & 157 & 184 & 163 & 170 & 154 \\
\hline \multicolumn{2}{r}{ Valor médio $=\mathbf{1 6 7} \mathbf{H V} \mathbf{0 , 5} \mathbf{~ k g}$} & & $\boldsymbol{\sigma}=\mathbf{\pm 1 2} \mathbf{H V} \mathbf{0 , 5} \mathbf{~ k g}$ \\
\hline
\end{tabular}

\subsection{Tamanho de Grão}

Neste procedimento foram realizadas três medições, uma com aumento de 1000X e duas com aumentos de 200X, e os resultados obtidos foram: 8,86; 8,30 e 8,75 $\mu \mathrm{m}$, respectivamente. Logo, o tamanho de grão da liga em estudo é de 8,64 $\mu \mathrm{m}$, com desvio padrão de $0,30 \mu \mathrm{m}$, sua nomenclatura de acordo com a norma ASTM E112 é G10, 5 [10].

\subsection{Ensaios de Tração}

Após a análise dos dados obtidos no equipamento os valores para as propriedades mecânicas a partir das curvas tensão-deformação e tensão-deformação plástica (figuras 8 e 9): módulo de elasticidade, tensão de escoamento, tensão limite de resistência à tração, tensão de ruptura, alongamento, redução de área, coeficiente de resistência e expoente de encruamento (tabela 4). Logo, os valores das propriedades mecânicas obtidos nos ensaios foram próximos aos fornecidos pelo fabricante da liga (tabela 1).

Tabela 4: Propriedades mecânicas obtidas no ensaio de tração.

\begin{tabular}{c|c|c}
\hline Propriedades & Média & Desvio Padrão \\
\hline $\mathrm{E}(\mathrm{GPa})$ & 207 & 4 \\
\hline$\sigma_{\theta}(\mathrm{MPa})$ & 303 & 4 \\
\hline$\sigma_{f}(\mathrm{MPa})$ & 297 & 189 \\
\hline$\sigma_{r}(\mathrm{MPa})$ & 462 & 3 \\
\hline Alongamento $(\mathrm{mm})$ & 19 & 2 \\
\hline $\mathrm{RA}(\%)$ & 32,61 & 3 \\
\hline $\mathrm{H}(\mathrm{MPa})$ & 753 & 18 \\
\hline $\mathrm{n}$ & 0,203 & 0,012 \\
\hline
\end{tabular}




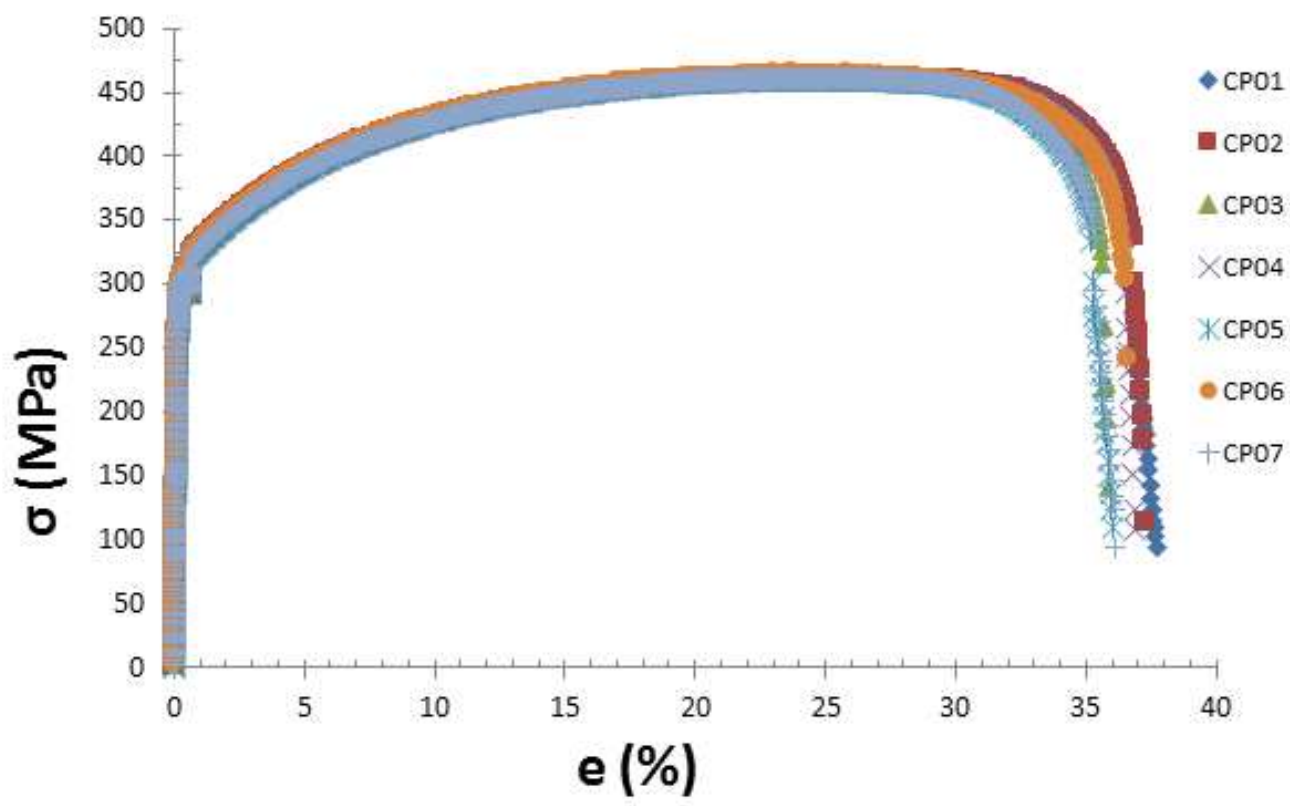

Figura 8: Curva tensão $(\sigma)$ - deformação (e), convencionais, obtida com os resultados do ensaio de tração.

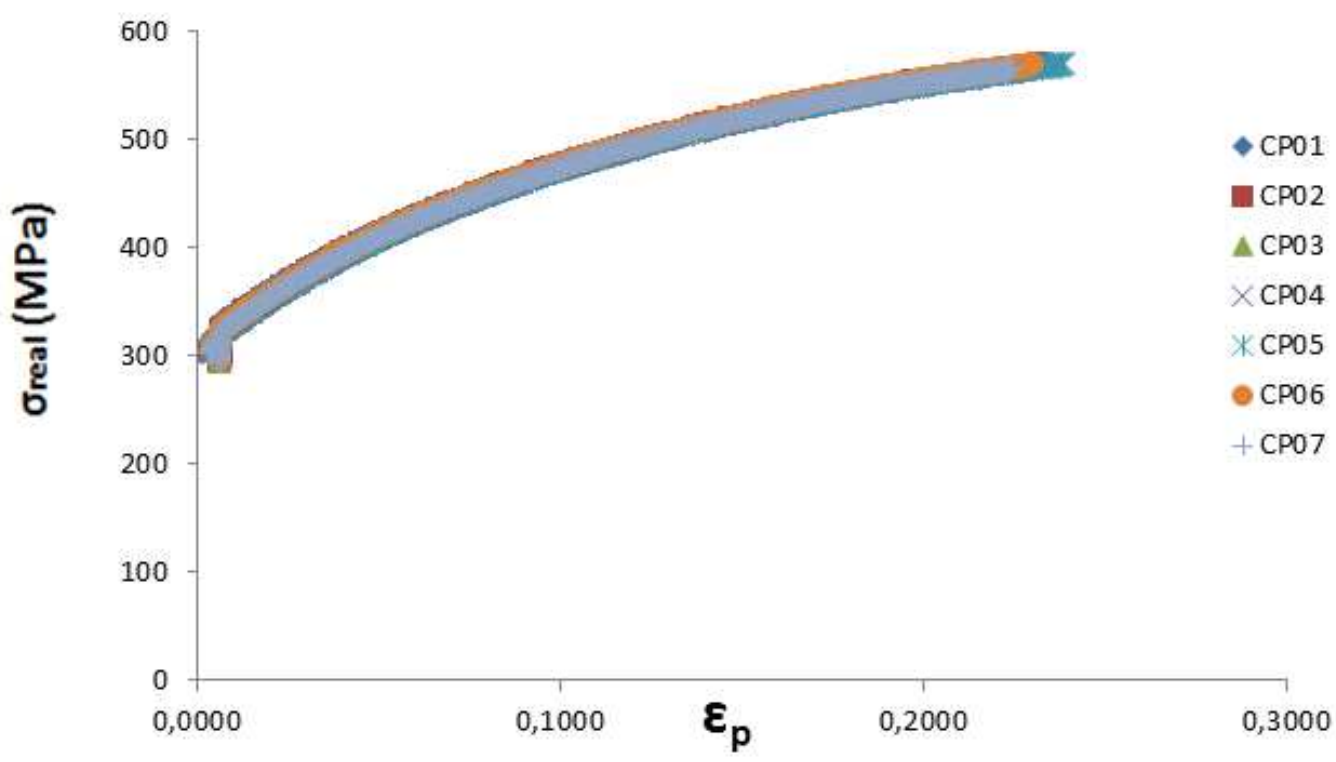

Figura 9: Curva tensão $(\sigma)$ - deformação plástica $\left(\varepsilon_{\mathrm{p}}\right)$, reais, trecho plástico, para obtenção do coeficiente de resistência $(H)$ e o expoente de encruamento $(n)$, obtida com os resultados do ensaio de tração.

\section{CONCLUSÕES}

A liga não possui orientação nos grãos, mesmo tendo sido laminada, portanto foi submetida a um tratamento térmico de recristalização que conduz a um aumento da tenacidade e ductilidade do material, pois ao diminuir as tensões residuais decorrentes da conformação plástica, possibilita que o material absorva mais energia antes de romper, esta capacidade de absorção de energia é uma propriedade fundamental no estudo de fadiga.

A liga UNS S43932, é um aço inoxidável ferrítico, e como todos os aços desta categoria possui baixo coeficiente de encruamento, em comparação com os aços inoxidáveis 
austeníticos (coeficientes de encruamento entre 0,3 e 0,45, em sua maioria) portanto praticamente não há aumento da resistência do material devido atuação de uma tensão que cause deformação a frio, logo sua vida em fadiga deve ser menor que a de um aço inoxidável austenítico.

Os resultados obtidos no ensaio de dureza e tração mostram-se muito próximos dos esperados, fornecidos pelo fabricante indicando que o ensaio foi realizado de forma correta e com grande exatidão. $E$, subsequentemente, as propriedades ainda desconhecidas da região plástica foram obtidas.

\section{REFERÊNCIAS}

1 SILVA e MEI, André Luiz V. da Costa e Paulo Roberto. Aços e Ligas Especiais. 3a ed. Blucher, 2010. C. 1, 5 e 7, p. $1-417$.

2 CALLISTER JR., W. D. Material Science and Engineering: an Introduction. $7^{\text {a }}$ ed. John Wiley \& Sons, Inc., 2007. c. 8, p. 167-174.

3 DOWLING, N. E. Mechanical Behavior of Materials. $3^{\mathrm{a}}$ ed. Pearson Prentice Hall, Inc. 2007. c. 9, p. 391-441.

$4 \quad$ ASM Metals Handbook. Fatigue. Vol 19. 2004.

5 APERAM. Aço inoxidável: a solução perfeita para o desenvolvimento sustentável. Disponível em: http://www.aperam.com/brazil/port/arquivos/Aco-Inoxidavel-Asolucaoperfeita-para-o-desenvolvimento-sustentavel.pdf. Acesso em 10/03/2015.

6 APERAM. Disponível em: http://www.aperam.com/uploads/stainlesseurope/South\%20America/Tubes\%20Brazil/C atalogo\%20Aperam_PT.pdf. Acesso em 10/03/2015.

$7 \quad$ ASM Metals Handbook. Metallography and Microstuctures. Vol 9. 2004.

8 American Society for Testing and Materials (ASTM). Standard practice for strain controlled fatigue testing. Standard E, 606 edition, 2001

9 American Society for Testing and Materials (ASTM). Standard Test Method for Bending Fatigue Testing for Copper-Alloy Spring Materials. B593-96. 2009.

10 American Society for Testing and Materials (ASTM). Standard Test Method for Knoop and Vickers Hardness of Materials. E384-11e1, 2012.

11 American Society for Testing and Materials (ASTM). Adjunct to E112 Methods for Determining the Average Grain Size. E112, 2012.

12 American Society for Testing and Materials (ASTM). Standard Test Methods of Tension Testing of Metallic Materials. E8M-03, 2013. 